\title{
Effect of high-energy ball milling in the structural and textural properties of kaolinite
}

\section{(Efeito da moagem de alta energia nas propriedades estruturais e texturais da caulinita)}

\author{
E. C. Leonel, E. J. Nassar, K. J.Ciuffi, M.J.dos Reis*, P. S.Calefi \\ Universidade de Franca, Av. Dr. Armando Salles Oliveira, Parque Universitário, 201, Franca, SP, Brasil 14404-600 \\ *reis.mj@gmail.com
}

\begin{abstract}
Through the process of high-energy ball milling it is possible to obtain solid materials with higher surface area and different particle sizes. These characteristics are very important for some application such as adsorption. Besides, applications of some clays depend on the functionalization which, for kaolinite, takes place in the aluminol groups. Modification in the structural and textural properties of kaolinite by high-energy milling can improve functionalization of kaolinite due to the exposure of aluminol groups. In this work studies were done on the influence of high-energy ball milling on the morphological properties of kaolinite, taking into account parameters such as filling of the miller, number of balls and amount of mass to be milled. Moreover, studies involving milling kinetics of purified kaolinite were carried out to verify modification in the morphology of kaolinite with milling time.
\end{abstract}

Keywords: kaolinite, high-energy milling, structural properties.

\section{Resumo}

Por meio do processo de moagem de alta energia é possível obter materiais sólidos com elevadas áreas superficiais e diferentes tamanhos de partículas. Estas características são muito importantes para algumas aplicações, tais como adsorção. Além disso, as aplicações de algumas argilas dependem da funcionalização que, para a caulinita, ocorrem nos grupos aluminóis. Modificações nas propriedades estruturais e texturais de caulinita por moagem de alta energia podem melhorar a funcionalização da caulinita devido à exposição dos grupos aluminóis. Neste trabalho, estudos foram feitos sobre a influência da moagem de alta energia nas propriedades morfológicas da caulinita levando-se em conta parâmetros tais como o preenchimento do moinho, o número de bolas utilizadas na moagem e a quantidade de massa a ser moída e também, estudos sobre a cinética de moagem de caulinita purificada foram feitos com a finalidade de verificar a variação na morfologia da caulinita com o tempo de moagem.

Palavras-chave: caulinita, moagem de alta energia, propriedades estruturais.

\section{INTRODUCTION}

\section{Kaolinite and new materials}

The study of the properties of new materials obtained by kaolinite functionalization is justified due to the low cost of this mineral clay and its possible industrial applications. New technologies involving hybrid materials represent a major advance and enable the improvement of chemical processes, as well as the replacement of materials and methods harmful to the environment. The inclusion by functionalization of organic molecules within the lamellar structure of kaolinite has been commonly reported $[1,2]$. Kaolinite is a mineral clay with lamellar structure formed by stacking lamellas. Each lamella consists of two crystal sheets: a sheet formed by tetrahedral silica $\left(\mathrm{SiO}_{2}\right)$ and one octahedral sheet formed by aluminol $(\mathrm{AlOH})$, both remaining cohesive by sharing oxygen atoms. In the interlamellar spacing, hydroxyls groups $(\mathrm{OH})$ of the kaolinite can react with organic substance, yielding chemical bonds between aluminum, carbon and oxygen (Al-O-C), characterizing the functionalization.

Typically, synthesis of the kaolinite hybrid material, functionalized with organic substance is prepared using a precursor material. The precursor is obtained by intercalation of a highly polar and small size molecule, as dimethylsulfoxide, in order to increase the interlamellar spacing. From the precursor, the synthesis of the hybrid material is possible by replacing dimethylsulfoxide by other molecule [3-5]. Without pre-intercalation, functionalization is only possible in the kaolinite surface. Hence, modification in the structural and textural properties of kaolinite by highenergy ball milling exposing inner aluminol groups can improve the functionalization of kaolinite [6].

\section{High energy ball milling}

Milling is a unit operation used in many industrial procedures using solid materials. The goal is basically to decrease particle size and/or to increase the surface area of the materials [6, 7]. Milling allows improvement of many 
industrial processes and has an increasing importance in engineering materials, being a process that can occur either continuously or batch wise. This technique cause changes in the microstructure refinement of particles and microdeformations in the crystal lattice of the solid material [7].

Many types of milling apparatus are described according to their shape and size. There are some apparatus for laboratory to mill little amounts of solid materials and industrial apparatus able to mill several tons. There are ball mills or hammers mills which rotate around one, two or three axes. Ball mills are called high-energy mill because of the large energy dissipated in the process of collision and friction of balls with the container wall [7].

High-energy ball milling is a relatively new technique that has applications in processes for obtaining nanostructured materials, or it is used in solid reactions. In the milling process, several parameters as the milling time, rotation speed, temperature, diameter and number of balls, container volume, and the sample mass to be ground, the ratio of mass of ball/mass of sample (RBS) must be defined. High-energy ball milling works by rotating the container where the balls and the solid to be milled are put inside. The mill named planetarium has both rotational and translational motions. The two motions are equal and opposite, i.e., the equipment support rotates clockwise whereas the milling container rotates counterclockwise. The balls into the mill are subjected to the action of centripetal forces involved in two planetary motions and, due to the opposite directions, they remain in the center of the container, rubbing and colliding with each other and with the base of the container [8]. There are six kinds of energy dissipation within the planetary mill: clash between the spheres, collision between ball and wall, friction between balls, ball-wall friction, pressure between ball and ball-wall pressure. The behavior of the sample during milling process depends primarily on the physical properties of the material being milled. The ductility is the most important property for the process. The difference between ductile and brittle materials determines the way in which variation of particle size occurs during the process $[7,9]$. An example of the application of high-energy ball milling is the formation of composites and nanocomposites using a starting material consisting of a mixture of two materials with different ductility. At the beginning of the milling process, the particles are fragmented and become ductile and flattened by micro-forging process. The flattened particles undergo welding, while the fragile particles are distributed on the surface of softer material, thus, there is an increased particle size. There is also simultaneous process in which the particles begin to be fractured, which tend to refine them. In a second stage the fracture process starts to become more common than welding. In the course of milling, both phenomena, welding and fracture, come into balance and the particles size is almost homogeneous. In extreme stages, the amorphization of the material takes place [8]. Besides the decrease of particle size the surface area of the materials is increased after high energy milling.

In this work, studies were made focusing on the influence of high energy ball milling process on the structural and textural properties of kaolinite, taking into account parameters such as filling of the miller, the number of balls and the amount of mass to be milled. Moreover, studies involving milling kinetics of purified kaolinite were performed to verify variation in morphology of kaolinite with milling time, considering that the milling process can expose the aluminol groups of kaolinite and thus, avoiding pre-intercalation. The materials obtained after the milling process were characterized by powder X-ray diffraction, scanning electron microscopy and thermal analysis.

\section{EXPERIMENTAL PROCEDURES}

Kaolinite was purified taking raw kaolinite in suspension in distilled water as described in the literature [2] and kaolinite intercalation was done by adding $40 \mathrm{~g}$ of purified kaolinite in $270 \mathrm{~mL}$ of DMSO and $30 \mathrm{~mL}$ of water. The resultant suspension was kept in shaking at $60^{\circ} \mathrm{C}$ for 10 days and the resultant material was separated by centrifugation and washed with ethanol and dried at $60{ }^{\circ} \mathrm{C}$.

The high energy milling was done in a mill Fritsch Pulverisette 5 planetary type. For initial studies on the kinetics of milling, $2 \mathrm{~g}$ of purified kaolinite and five stainless steel balls with $10 \mathrm{~mm}$ diameter were placed into a stainless steel container with a volume of $80 \mathrm{~mL}$ resulting in a RBS ratio of 10 , and $360 \mathrm{rpm}$ of rotation speed. The samples were milled at different times $(5,10,15,20,40$ and 60 $\mathrm{min})$ to verify the time effect. The obtained materials were characterized by powder X-ray diffraction (PXRD) and scanning electron microscopy (SEM).

Into another set of conditions (RBS ratio 50 and 30 min), purified kaolinite and kaolinite intercalated with dimethylsulfoxide (DMSO) were milled for comparison. Purified kaolinite is denominated $\mathrm{P}$ before and PM after milling, and similarly, intercalated kaolinite is denominated PI before and PIM after milling. These materials produced were characterized by PXRD, SEM, FT-IR and thermal analyses.

\section{Characterization techniques}

$X$-ray diffraction: powder X-ray diffraction (PXRD) measurements were performed in a Siemens D5005 X-ray diffractometer, with a graphite monochromator selecting the $\mathrm{Cu}-\mathrm{k} \alpha_{1}$ radiation $(0.15406 \mathrm{~nm})$ in an angular $2 \theta$ range of $2-75^{\circ}$ and step rate of $0.04^{\circ} \mathrm{s}^{-1}$.

Infrared spectroscopy: Fourier-transform infrared spectra (FT-IR) were recorded on an ABB Bomem MB 100 spectrometer over the range $400-4000 \mathrm{~cm}^{-1}$ with 32 scans and $4 \mathrm{~cm}^{-1}$ resolution, using pressed $\mathrm{KBr}$ pellets at $2 \%(\mathrm{w} / \mathrm{w})$ of dispersed sample.

Thermal analyses: thermogravimetric analyses (TGA) were performed in a TA Instruments SDT 600. The samples were heated in synthetic air atmosphere (White Martins - 80\% $\mathrm{N}_{2}$ and $20 \% \mathrm{O}_{2}$ ) with flux of $100 \mathrm{~cm}^{3} \cdot \mathrm{min}^{-1}$. Heating rate of $10{ }^{\circ} \mathrm{C} \cdot \mathrm{min}^{-1}$ was used for all samples, from $25^{\circ} \mathrm{C}$ to $900{ }^{\circ} \mathrm{C}$. 
Scanning electron microscopy: morphology and surface characteristics of the materials were analyzed with a scanning electron microscopy in a Zeiss EVO50 scanning electron microscope ( $20 \mathrm{kV}$ and mag. $30 \mathrm{kX}$ ). All powder samples were fixed in a support and before analysis they were metalized by gold coating (during $100 \mathrm{~s}, \mathrm{I}=40 \mathrm{~mA}$ ), ina Bal-Tec SCD 050 sputter coater system. This procedure was done to improve conductivity of samples to provide images with good quality.

\section{RESULTS AND DISCUSSION}

Fig. 1 shows the X-ray diffractograms of the purified kaolinite milled at different times $(5,10,15,20,40$ and $60 \mathrm{~min}$ ). It is possible to observe a decrease in diffraction intensity of the main peaks $(001)$ at $2 \theta 12.4^{\circ}$, characteristic of lamellar kaolinite, along milling time characterizing loss of crystallinity of the samples. Similar phenomenon is observed at the second order diffraction peak located near to $2 \theta 25^{\circ}$. However, the intensity of the peak near to $2 \theta$ equal to $20^{\circ}$ seems not change so significant. These peaks are related to refraction characteristics of nanocrystalline morphology of kaolinite. A little change in the intensity of these peaks provides evidence that milling exerts small influence on the internal structure of kaolinite crystallite, i.e. kaolinite crystallites are reduced by milling, and however, there is no destruction of the kaolinite lamellae.

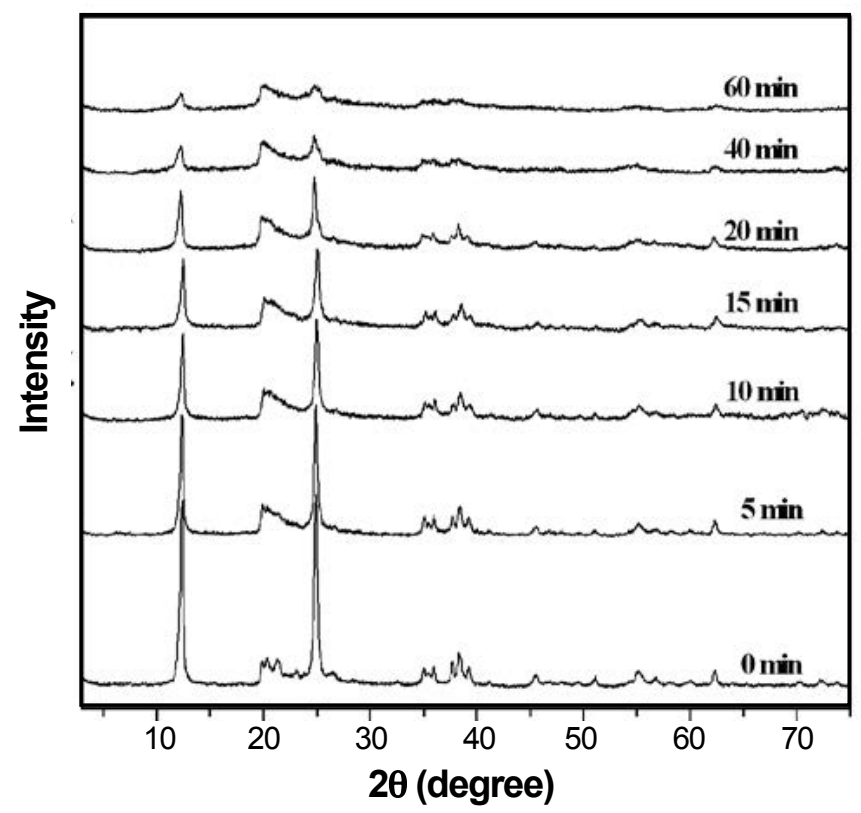

Figure 1: Powder X-ray diffraction patterns obtained for purified kaolinite milling at different times.

[Figura 1: Padrões de difração de raios $X$ obtidos para caulinita purificada moída em diferentes tempos.]

The variation of the first peak along with the milling time is showed in Fig. 2. During the first minutes there is a large rate of change of intensity, and along time this parameter decreases until reaching the minimum value between 40 and $60 \mathrm{~min}$. This behavior corresponds to an exponential decay of second order, suitable to the equation $\mathrm{A}$, where $\mathrm{I}_{0}=14337.5$ and $\mathrm{k}=6.65 \mathrm{e}^{-6}$.

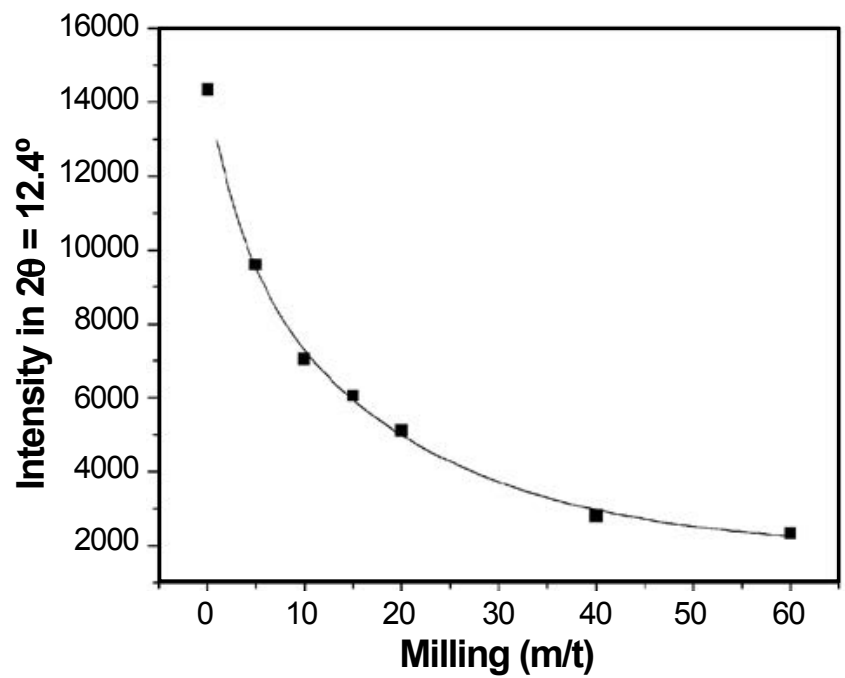

Figure 2: Variation of peak intensity in $2 \theta 12.4^{\circ}$ along the milling time.

[Figura 2: Variação da intensidade do pico em $2 \theta \quad 12,4^{\circ}$ ao longo do tempo de moagem.]

$$
\mathrm{I}=\mathrm{I}_{0} /\left(\mathrm{k} \cdot \mathrm{I}_{0} \cdot \mathrm{t}+1\right)
$$

Besides intensity, other important factor in determining the crystallinity of the material is the shape of the peak, as well as a possible displacement thereof. The narrower is the peak is more crystalline material. It is known, however, that the broadening of peaks may also be due to overlapping of two or more narrow peaks. Thus, variations in shape and peak position must be considered altogether. Fig. 3 shows the values of the peak width ( $2 \theta$ equal to $12.4^{\circ}$ ) in average height determined by the XRD patterns for samples obtained at different times as function of milling time. The results show an increasing pattern which helps confirm the tendency

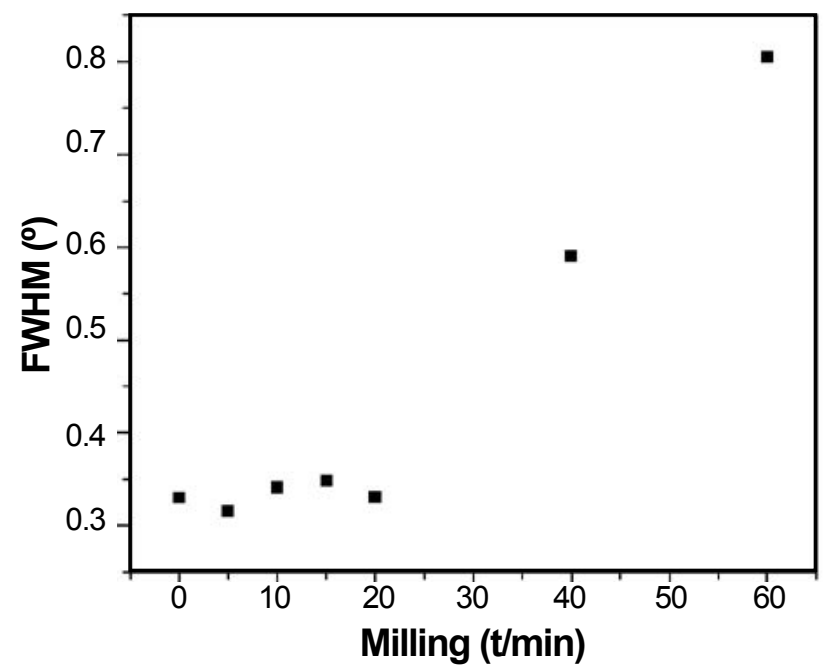

Figure 3: Full width at half maximum (FWHM) as function of time. [Figura 3: Largura do pico na altura média (LPAM) em função do tempo.] 
of the material to become amorphous with increasing time of high energy milling.

Fig. 4 shows the $2 \theta$ peak position by each milling time. Divided into three stages, the pattern of variation is characterized by successive increases and decreases in the values of $2 \theta$. There was an initial shift to higher $2 \theta$ values. Between times of 15 to $20 \mathrm{~min}$ greater variation is observed from $12.5^{\circ}$ to $12.28^{\circ}$. The third stage occurs with growth of $2 \theta$ values up to $12.35^{\circ}$. Although variations are small, the results show the existence of a pattern which relates the peak position with the milling time.

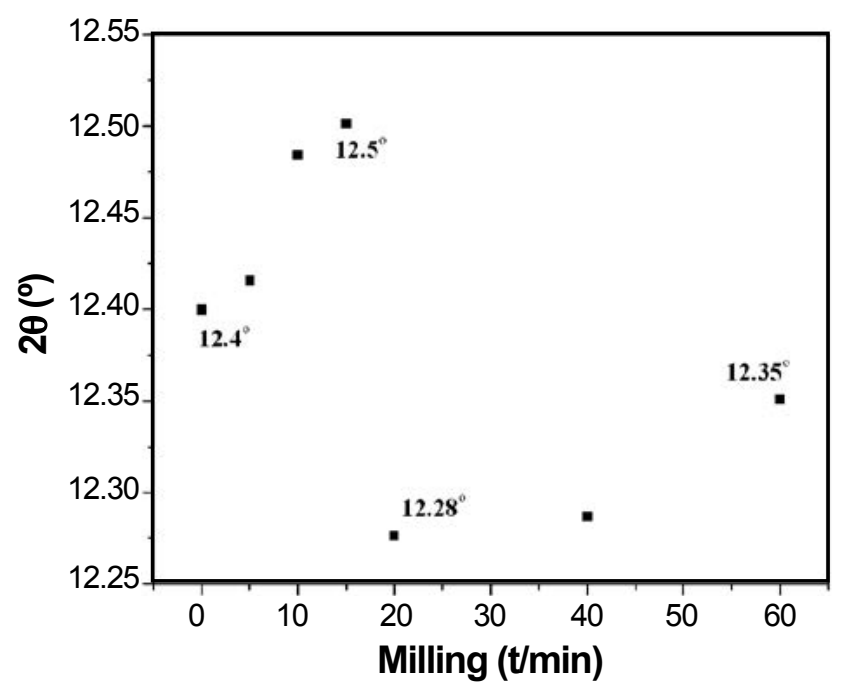

Figure 4: Peak position related to the milling time.

[Figura 4: Posição do pico relativo ao tempo de moagem.]

The results observed in Figs. 3 and 4 show the existence of different morphological transformation phenomena which occur simultaneously along with the milling process. These phenomena can be explained based on the kaolinite properties such as ductility and brittleness. The break by fatigue of fragile particles during the milling process, while providing a decrease in particle size, contributes to a small decrease in the interlamelar spacing. In Fig. 3, it can be observed that during the first five min of milling a decrease in the width of the peak demonstrating the formation of slightly more homogeneous material in comparison with the material before the milling process. Breakage of fragile particles by fatigue continues to dominate the process until the $15 \mathrm{~min}$ of milling. Between 15 and $20 \mathrm{~min}$, there was a rapid decrease in the values of $2 \theta$ (Fig. 4). This event demonstrates an increase in basal spacing, which occurs simultaneously with a slight decrease in peak width (Fig. 3). From $20 \mathrm{~min}$, both the results of Fig. 3 as those in Fig. 4 , show growth. This characterizes basal spacing decreasing and material amorphization, simultaneously. The reduction of crystallinity can be observed in the images of the samples obtained by scanning electron microscopy presented in Fig. 5. It is possible to observe a decrease in particle size with increasing milling time, as well as the agglomeration of small particles that are under formation. With $5 \mathrm{~min}$ milling it is still possible to perceive the presence of crystalline materials with relatively big size. After $15 \mathrm{~min}$, it was observed that small particles begin to undergo a sintering process forming heterogeneous agglutination. Upon $40 \mathrm{~min}$ of milling the sample seems to reach the apex of agglutination and it is characterized by clearly unequal sizes. There is a large body of fused particles surrounded by other particles dispersed in nanometer dimensions. In the micrograph of the material milled for $60 \mathrm{~min}$ interesting events can be observed, i.e., the formation of fibrous structures. It is noted in this micrograph quite irregular mixture of materials with different morphologies: a large agglomerated particle, small pieces and nanoscale structures that resemble fiber disorder. This event demonstrates the beginning of a new morphological transformation process.
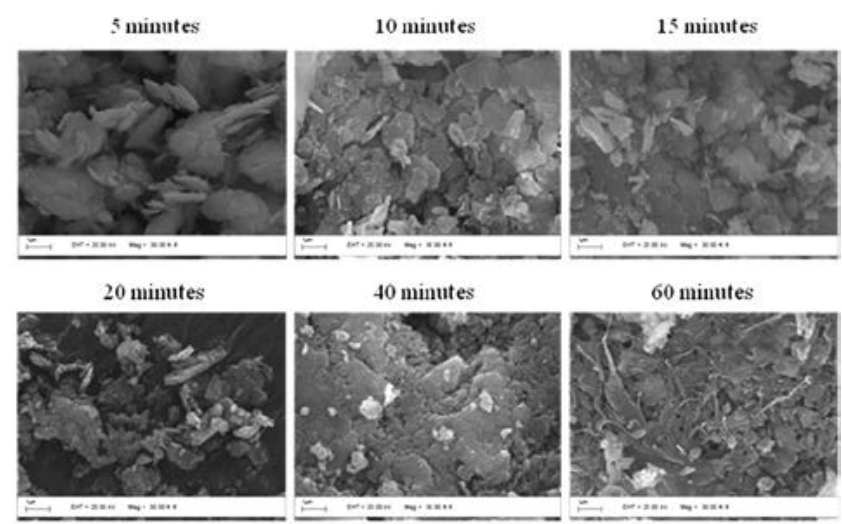

Figure 5: Scanning electron micrographs of purified kaolinite milling at different times.

[Figura 5: Micrografias de microscopia eletrônica de varredura da caulinita purificada moída em diferentes tempos.]

Fig. 6 shows the results of absorption spectroscopy in the infrared (FTIR) for the purified kaolinite and purified kaolinite milled at 5, 20 and $60 \mathrm{~min}$. A similarity in the

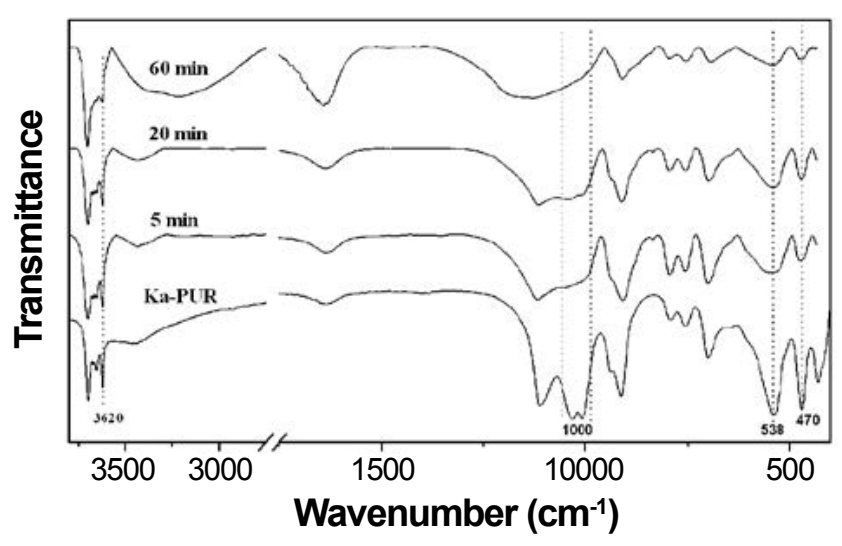

Figure 6: Absorption spectra in the infrared region obtained for materials: purified kaolinite (Ka-PUR) purified kaolinite milled at 5, 20 and $60 \mathrm{~min}$.

[Figura 6: Espectro de absorção na região do infravermelho obtido para materiais: caulinita purificada (Ka-PUR) caulinita purificada moída em 5, 20 e 60 min.] 
spectra is observed for kaolinite milled at different times. The absorption bands that characterize the energetic vibrations of the kaolinite functional groups had no significant displacements, changing only the intensity [5]. The main difference observed in the spectra corresponds to the absorption band in $1000 \mathrm{~cm}^{-1}$ due to the stretching energy of Si-O-Si in the silicon tetrahedral sheet.

Fig. 7 shows X-ray diffractograms obtained for P, PI, PM and PIM. The diffraction patterns obtained for the two materials after milling are very similar and emphasize the amorphization and the loss of crystallinity are equal, and it means that textural properties after milling is independent of intercalation process.

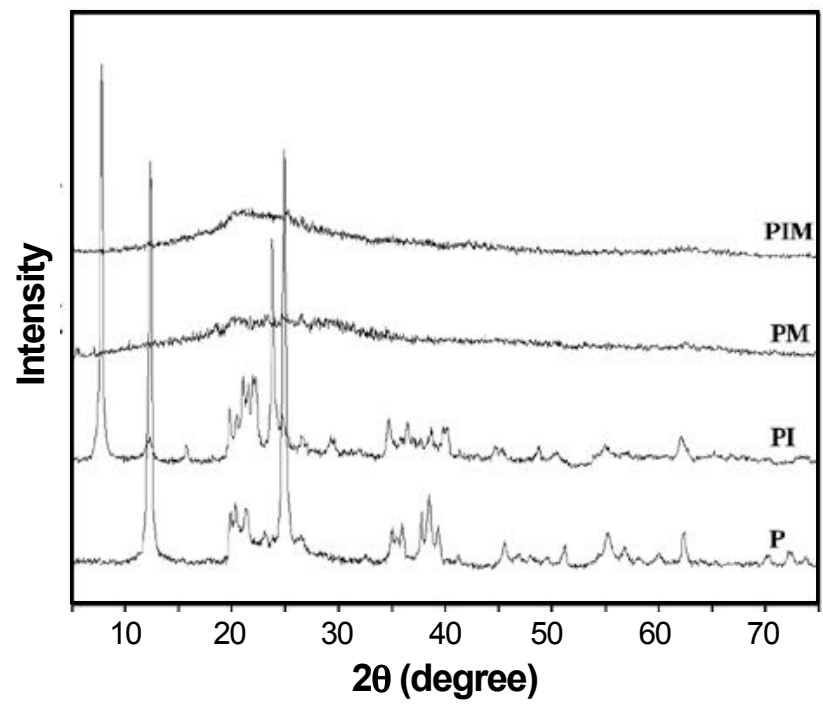

Figure 7: XRD patterns of the purified kaolinite before $(\mathrm{P})$ and after milling (PM), intercalated kaolinite before (PI) and after milling (PIM).

[Figura 7: Padrões de difração de raios $X$ da caulinita purificada antes $(P)$ e depois da moagem (PM), caulinita intercalada antes (PI) e depois da moagem (PIM).]

The thermogravimetric curves obtained from thermal decomposition of purified kaolinite before and after milling are presented in Fig. 8 and the results show that the two materials are thermally very different. Before milling, kaolinite has a higher thermal stability, undergoing loss of water by decomposition of hydroxyl groups in a single step at approximately $500{ }^{\circ} \mathrm{C}$. After milling, water loss by dehydroxylation occurs from very low values of temperature. The variation of the total mass of the materials was approximately the same. This suggests that during milling the mass of the sample remains constant, with no evaporation of water, which could take place as a result of condensation of the hydroxyl aluminol [10].

Fig. 9 shows the thermogravimetric derivatives curves from TG and it is possible to perceive the difference of the two values occurs where the maximum rate of change of mass. While the dehydroxylation in purified kaolinite $(\mathrm{P})$ occurs near $500{ }^{\circ} \mathrm{C}$, the kaolinite ground (PM) this same phenomenon occurs near $130^{\circ} \mathrm{C}$. This difference shows that milling under the selected conditions, was able to expose the

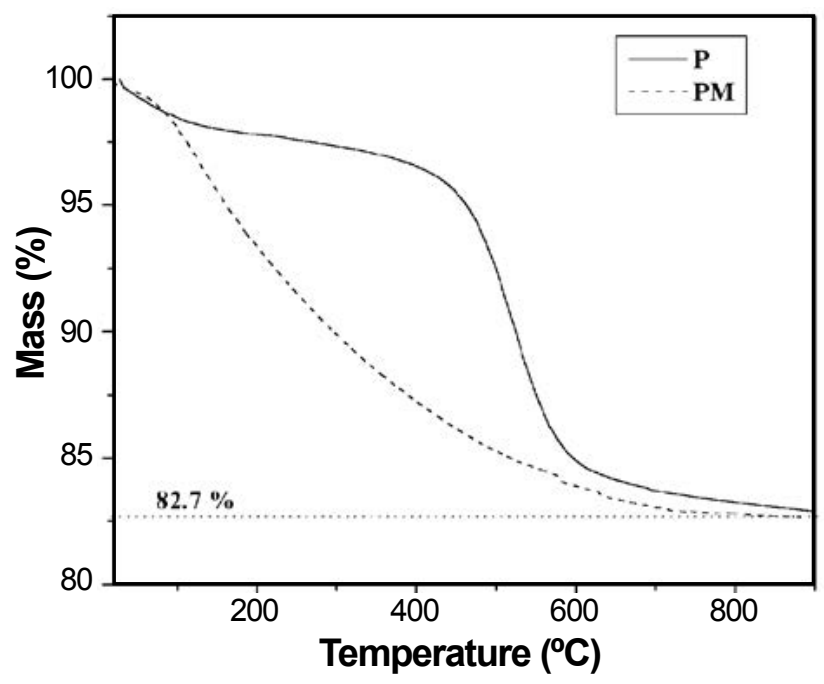

Figure 8: Thermogravimetric curves of purified kaolinite before $(\mathrm{P})$ and after milling (PM).

[Figura 8: Curvas termogravimétricas da caulinita purificada antes $(P)$ e depois da moagem (PM).]

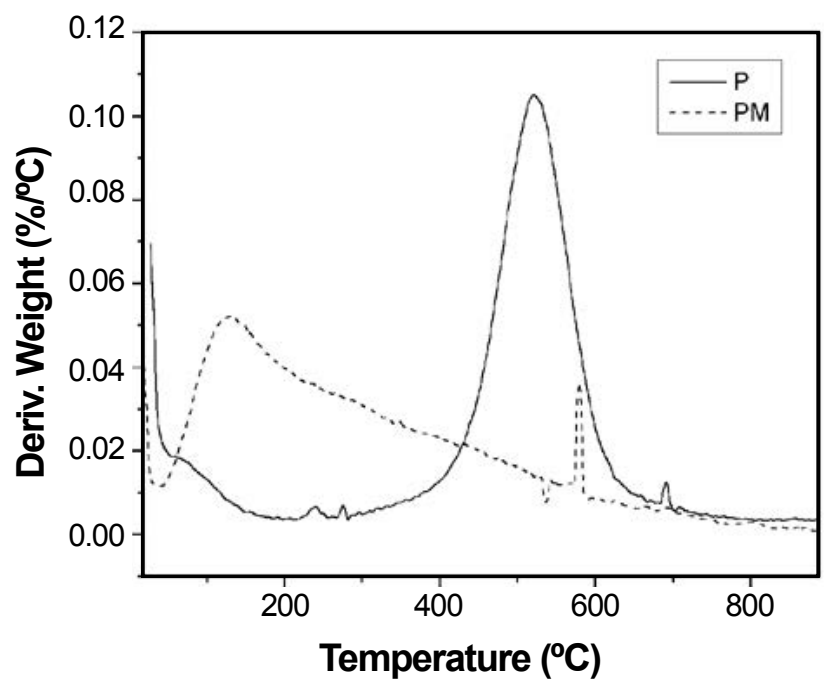

Figure 9: Derivative of thermogravimetric curves (DTG) obtained from the purified kaolinite before and after milling.

[Figura 9: Derivada das curvas termogravimétricas (DTG) obtidas a partir da caulinita purificada antes e depois da moagem.]

aluminol hydroxyls of kaolinite, which is why condensed with less energy.

\section{CONCLUSIONS}

Milling purified kaolinite is possible to obtain different materials with specific morphological configurations. The high energy ball milling technique proved a very useful technique, with potential applications in the preparation of hybrid materials of kaolinite. Through this process, during the milling kinetics study, it was possible to observe the occurrence of stages of structural transformation of kaolinite. These stages are a result of the simultaneous 
occurrence of the fatigue phenomena and breakage by micro-forging. These phenomena are, by their turn, related to the ductility properties of kaolinite. The microscopic images showed that milling kaolinite, under specific conditions, can produce materials with fibrous structure. This property makes the process of high energy ball milling very interesting to prepare kaolinite to be used as filler for various products and industrial processes. The thermal analysis of milled kaolinite showed an opening of the structure of clay minerals with exposure of aluminol, a fact related to the loss of water at temperatures much lower than the one that happens in the no-milled material. These promising results suggests the use of milling in the preparation of hybrid kaolinite, because the exposure to aluminol groups may promote reactions with organic molecules.

\section{ACKNOWLEDGEMENTS}

The authors thank the Brazilian agencies CAPES and $\mathrm{CNPq}$ for financial support.

\section{REFERENCES}

[1] F. Bergaya, B. K. G. Theng, G. Lagaly, "Handbook of Clay Science", Elsevier (2006).

[2] C. Detellier, B. B. Kerstin, T. A. Elbokl, J. Mater. Chem. 13 (2003) 2566.

[3] R. L. Frost, J. Kristof, E. Horvath, J. T. Kloprogge, J. Phys. Chem. 103 (1999) 9654.

[4] R. L. Frost, J. Kristof, G. N. Paroz, J. T. Kloprogge, J. Phys. Chem. 102 (1998) 8519.

[5] R. L. Frost, W. N. Martens, J. Kristof, E. Horvath, J. Phys. Chem. 106 (2002) 4162.

[6] H. Cheng, Q. Liu, J. Zhang, J. Yang, R. L. Frost, J. Colloid Interface Sci. 348 (2010) 355.

[7] T. Hongo, S. Yoshino, A. Yamazaki, S. Satokawa, Appl. Clay Sci. 70 (2012) 74.

[8] C. Suryanarayana, Progr. Mater. Sci. 46 (2001) 1.

[9] D. L. Zhang, Progr. Mater. Sci. 49 (2004) 537.

[10] F. Sahnoune, N. Saheb, B. Khamel, Z. Takkouk, J. Thermal Anal. Calorim. 107 (2012) 1067.

(Rec. 22/01/2014, Ac. 29/01/2014) 